\title{
Motivators of seeking pelvic floor physical therapy in ultra- orthodox Jewish women
}

\author{
(1) LEA TENE ${ }^{1,2}$, (1) MENAHEM NEUMAN ${ }^{1,3}$, (1) LEONID KALICHMAN², (1) JACOB BORNSTEIN ${ }^{1,3}$ \\ 1Department of Obstetrics and Gynaecology, Galilee Medical Center, Nahariya, Israel \\ 2Department of Physical Therapy, Recanati School for Community Health Professions, \\ Faculty of Health Sciences, Ben-Gurion University of the Negev, Beer-Sheva, Israel \\ ${ }^{3}$ Department of Obstetrics and Gynaecology, Azrieli Faculty of Medicine, Bar Ilan University, Safed, Israel
}

\section{ABSTRACT}

Objective: Almost 50\% of women with one or more children experience pelvic organ prolapse, and physical therapy for pelvic floor rehabilitation is one of the first-line treatments for women with pelvic organ prolapse seeking medical care. This study aimed to investigate whether ultraorthodox women would proceed with pelvic floor rehabilitation taking into account Jewish religious laws—Halacha—or medical motivations.

Materials and Methods: Between January and May 2015, 65 ultra-orthodox women aged 20-65 undergoing pelvic floor rehabilitation completed a questionnaire regarding their pelvic floor function, religion, and treatment motivations.

Results: Most women considered both medical and Jewish religious law reasons for seeking treatment for pelvic organ prolapse (POP).

Sixty-five women completed the survey. More women sought treatment taking into consideration both medical and Jewish religious law reasons, as opposed to medical or Jewish religious law reasons alone. Upholding religious commandments was an important factor in seeking medical treatment.

The motivation to seek treatment for POP symptoms usually involves both medical and religious law reasons in ultra-orthodox Jewish women.

The study's strength is that it is novel in examining the religious motivations for seeking therapy for symptoms associated with POP. However, no control group was included in this study, which is a limitation.

Conclusion: The findings indicate that Jewish religious law motivations were an extremely important factor among ultra-orthodox women presenting for pelvic floor rehabilitation.

Keywords: Pelvic floor; pelvic floor rehabilitation; physical therapy; treatment; ultra-orthodox

\section{INTRODUCTION}

Pelvic floor medicine deals with the treatment of tissue, muscle, and ligament deficiencies in the pelvic floor. These deficiencies sometimes result in urinary and fecal incontinence, sexual dysfunction, organ prolapse, and organ dysfunction. ${ }^{1}$ Each symptom deeply affects a woman's quality of life. ${ }^{2}$ Religious,

Address for Correspondence: Jacob Bornstein, Department of Obstetrics and Gynaecology, Galilee Medical Center, Nahariya, Israel and Department of Obstetrics and Gynaecology, Azrieli Faculty of Medicine, Bar Ilan University, Safed, Israel

E-mail: mdjacob@gmail.com ORCID ID: orcid.org/0000-0003-1932-5270

Received: 15 January 2021 Accepted: 29 January 2021

${ }^{\circledR}$ Copyright 2021 by the International Society for Pelviperineology / Pelviperineology published by Galenos Publishing House. 
especially ultra-orthodox Jewish women suffer twofold: everyday functioning is impaired, and their ability to properly fulfil religious commandments is damaged. In the ultra-orthodox Jewish community, the Jewish religious law-Halacha-has a great influence on every aspect of life. Thus, a medical problem will be handled when it is medically disturbing and especially when the problem leads to a conflict with Jewish religious law and the ability to fulfil religious commandments.

Urinary incontinence can arise from physical effort, ${ }^{3}$ leading to inability to restrain urine release, which impairs quality of life. Fecal incontinence is associated with impaired activity of the pelvic floor sphincters; however, its social consequences are far more extensive. ${ }^{4,5}$ Between $9 \%$ and $39 \%$ of women aged over 60 report daily urinary leaks, ${ }^{6}$ whereas the prevalence of fecal incontinence is between $2 \%$ and $6 \%{ }^{7}$ It affects approximately $9 \%$ of women during the first 3 months postpartum. ${ }^{4}$ Moreover, when lack of gas control is considered, the frequency is even higher. Pelvic organ prolapse (POP) is a condition in which one or more pelvic organs have descended. It can occur with each of the pelvic organs, in part of an organ, or in several organs together. ${ }^{8}$ Prolapse occurs when the pelvic ligaments and muscles are damaged, weak, or under high or continuous pressure. ${ }^{9}$ Almost $50 \%$ of women with one or more children experience prolapse, and among them, $10 \%-20 \%$ are symptomatic. ${ }^{10}$

In this study, we focused on pelvic floor rehabilitation with regard to three conditions: incontinence, POP, and pain during vaginal intercourse. The aim of this study was to examine whether Jewish religious law repercussions are an additional cause for ultraorthodox women to seek pelvic floor rehabilitation treatment, beyond the general medical motivation common to all women. We hypothesized that ultra-orthodox women attribute great importance to the Jewish religious law implications of a medical issue and seek pelvic floor physical therapy based on medical reasons and their ability to fulfil religious commandments.

\section{MATERIALS AND METHODS}

This study was conducted among ultra-orthodox religious women from the ultra-orthodox cities of Bnei Brak and Elad. The inclusion criteria were women aged 20 to 65 years who presented for pelvic floor rehabilitation and who agreed to fill out the questionnaire.

Ethics: This study was performed in line with the principles of the Declaration of Helsinki. The IRB at Galilee Medical Center (Helsinki Committee) approved this study (approval number: 0058-20-NHR, given on July $21^{\text {st }}, 2020$ ). Participation in the study was voluntary. Patients who met the inclusion criteria received an explanation of the methods and procedures of the study, and if they were interested in participating, they signed an informed consent form. After signing the form, they filled out the questionnaire in a separate room next to the clinic. They were requested to complete the questionnaire anonymously after completing all treatment procedures, so that patient-therapist relationships to not affect their answers.

Tools: The questionnaire included 140 questions and was based on several Hebrew questionnaires as well as questions relevant to the topic of research. It was developed by the researchers and adapted to the unique topic of research and the target population. The questionnaire used a Likert scale where 1 expressed disagreement with the statement, opinion, or action, and 5 expressed strong agreement. For some of the questions, it was also possible to mark 6-irrelevant-because not all women experience the same symptoms.

After asking for the patients' demographic information, the questionnaire was divided into eight groups of statements according to subject. In each group, the means of the answers on a scale of 1 to 5 or 1 to 6 were calculated.

\section{Procedure}

The data were collected in pelvic floor rehabilitation clinics in Bnei Brak and Elad by a single researcher (L.T.). The study continued until the desired number of subjects was reached. Questionnaires were in Hebrew and were filled out anonymously.

\section{Statistical analysis}

All statistical computations were performed using SPSS 21.0 for Windows (SPSS, Chicago, IL, USA). Descriptive statistics were used to characterize the sample, and the data are presented as means with standard deviation (SD) or as proportions. To examine the significance of the statements, we used different analyses. We compared the differences between the two age groups (20-50 and $50+$ years) using a chi-square test. To check the ranking of sections dealing with the same domain, we used ANOVA for repeated measures. This process upgraded the sections, from the highest-average to the lowest-average section.

\section{RESULTS}

A total of 65 women, who identified as ultra-orthodox, completed the survey, and their demographic characteristics are presented in Table 1. The average age of the participants was 37.5 years ( $\mathrm{SD}=1.57)$, ranging between $21-63$ years, and most $(95.4 \%)$ were married. The majority of the participants (78.5\%) were native Israelis; of the remaining participants, four were from Turkey, Yemen, and Morocco (6.2\%), four from France and Belarus (6.2\%), one from Argentina (1.5\%), and five were from the United States 
(7.7\%). The majority (66.2\%) of the participants had studied in a seminar, and $80 \%$ of the women declared that they were currently working. Only a few (6.2\%) participants were pregnant at the time of the survey. Table 2 presents the three conditions of pelvic floor impairments that were studied. In the questionnaire, participants were asked to indicate the impairments from which they suffered and to answer the questions relevant to their

\begin{tabular}{|c|c|c|}
\hline \multicolumn{2}{|l|}{ Characteristic } & $\mathrm{N}=65(\%)$ \\
\hline \multirow{2}{*}{ Age } & $20-50$ & $52(80.0)$ \\
\hline & $50+$ & $13(20.0)$ \\
\hline \multirow{4}{*}{ Religious status } & Ultra-orthodox & $65(100)$ \\
\hline & Nationalist-religious & $0(0)$ \\
\hline & Traditional & $0(0)$ \\
\hline & Unknown & $0(0)$ \\
\hline \multirow{4}{*}{ Marital status } & Divorced & $2(3.1)$ \\
\hline & Widow & $1(1.51)$ \\
\hline & Married & $62(95.4)$ \\
\hline & Unmarried & $0(0)$ \\
\hline \multirow{5}{*}{ Region of origin } & Israel & $51(78.5)$ \\
\hline & Asia and Africa & $4(6.2)$ \\
\hline & Europe & $4(6.2)$ \\
\hline & South America & $1(1.5)$ \\
\hline & North America & $5(7.7)$ \\
\hline \multirow{5}{*}{ Education } & $<12$ years & $0(0)$ \\
\hline & $=12$ years & $10(15.4)$ \\
\hline & Seminar & $43(66.2)$ \\
\hline & College/B.A. degree & $11(16.9)$ \\
\hline & M.A. degree & $1(1.5)$ \\
\hline \multirow{2}{*}{ Currently working } & Yes & $52(80.0)$ \\
\hline & No & $13(20.0)$ \\
\hline \multirow{2}{*}{ Currently pregnant } & Yes & $4(6.2)$ \\
\hline & No & $61(93.8)$ \\
\hline $\begin{array}{l}\text { Number of children } \\
\text { (mean } \pm \text { standard } \\
\text { deviation) }\end{array}$ & - & $5.6 \pm 3.6$ \\
\hline
\end{tabular}

\begin{tabular}{|l|l|l|}
\hline \multicolumn{3}{|l|}{ Table 2. Presence of pelvic floor impairments* } \\
\hline Characteristics & Nes & $48(73.8)$ \\
\hline \multirow{2}{*}{ Urinary or fecal incontinence } & No & $17(26.2)$ \\
\hline \multirow{2}{*}{ Prolapse of one or more pelvic organs } & Yes & $29(44.6)$ \\
\cline { 2 - 3 } & No & $36(55.4)$ \\
\hline \multirow{2}{*}{ Difficulty or pain during intercourse } & Yes & $20(30.8)$ \\
\cline { 2 - 3 } & No & $45(69.2)$ \\
\hline *Women could suffer from more than one impairment \\
\hline
\end{tabular}

condition. As shown in Figure 1, 100\% of the women aged 50+ years reported urinary incontinence, compared to $67 \%$ of those aged between 20-50 years. This difference was statistically significant $(p=0.02)$. In terms of prolapse, $38.5 \%$ of women aged $50+$ years reported prolapse compared to $46.2 \%$ of women aged 20-50 years, which was not statistically significant. Women aged 20-50 years were significantly more likely to report sexual difficulties than those aged over 50 (36.5\% vs $7.7 \%$, respectively; $p=0.04)$.

Figure 2 shows the mean period of time in years from symptom appearance to questionnaire completion. This period was the shortest for women with fecal incontinence $(M=1.5$ years, $S D=1.00)$. The time period between symptom onset and questionnaire completion was longest among women with urinary incontinence. This finding may be related to the time taken for a patient to obtain a medical referral, which does not always coincide with the appearance of symptoms.

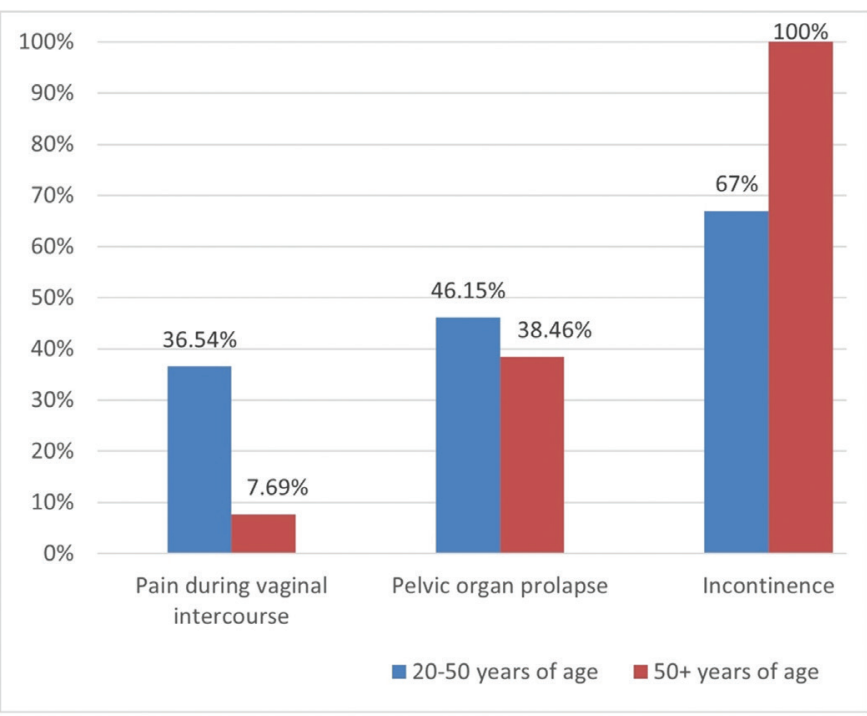

Figure 1. Pelvic floor dysfunction by age $(\mathrm{N}=65)$

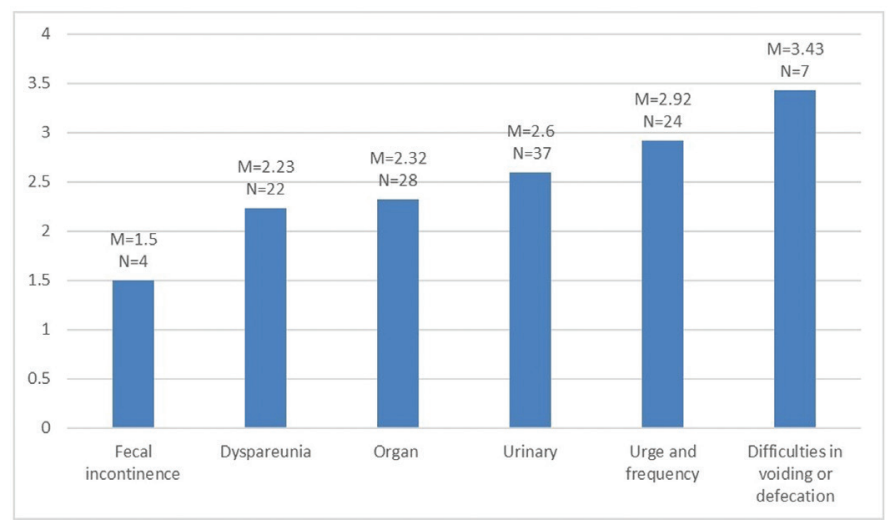

Figure 2. Average time between symptom onset and presentation for treatment

M: mean, N: Number 
We then asked the following question with regard to each of the three main pelvic floor disorders: "In general, if you were asked to define the most crucial motivation when referring to physical therapy treatment, what is your answer?" of the 42 women experiencing urinary incontinence, $50 \%$ reported both Halacha and medical motivations to seek treatment, whereas $45.2 \%$ reported solely medical motivation, and $4.8 \%$ reported solely Jewish religious law motivation (Figure 3). Of the 28 women experiencing POP, 42.9\% reported combined motivations, 39.3\% reported solely medical motivation, and $17.9 \%$ reported solely Jewish religious law motivation (Figure 4). Of the 19 women who reported pain during vaginal intercourse, $63.2 \%$ reported combined medical and Jewish religious law motivations, 21.1\%

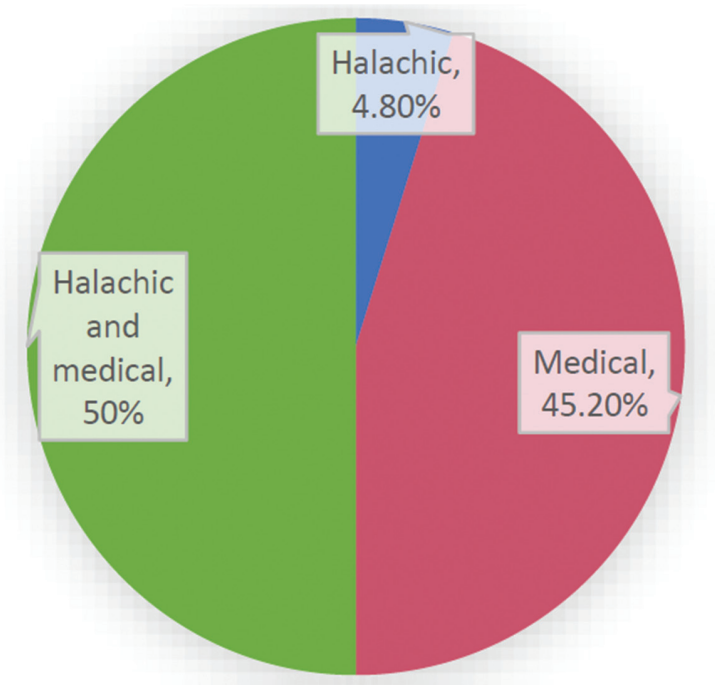

Figure 3. Motivation to pursue physical therapy ( $\mathrm{N}=42)$ Halachic: Related to Halacha, the Jewish religious law; N: Number

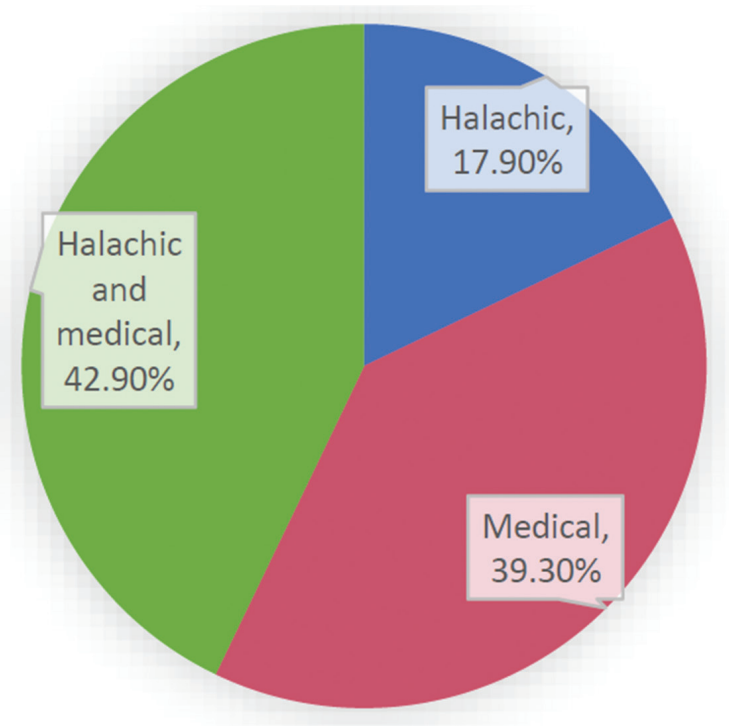

Figure 4. Most important motivation to seek treatment for pelvic organ prolapse $(\mathrm{N}=28)$

Halachic: Related to Halacha, the Jewish religious law; N: Number reported solely medical motivation, and $15.8 \%$ reported solely Jewish religious law motivation (Figure 5).

All women, regardless of their specific pelvic floor disorders, were asked about Jewish religious law or medical motivations for treatment (Figure 6). Of the 65 women who reported whether they had Jewish religious law or medical motivations to pursue treatment for each of their particular symptoms, only 3.1\% reported only Jewish religious law motivations for all disorders. While $23.1 \%$ reported only medical motivations for all disorders, 73\% reported combined medical and Jewish religious law motivations for seeking treatment.

The Jewish religious law was shown to be an extremely important aspect of life for ultra-orthodox women with their responses to statements such as "Religion plays a central part in my life" (mean $=4.84, \mathrm{SD}=0.35$ ) and "I feel obligated to fulfil religious commandments" (mean=4.94, SD=2.42).

When asked which situations would cause them to seek treatment immediately, difficulty getting pregnant because of a

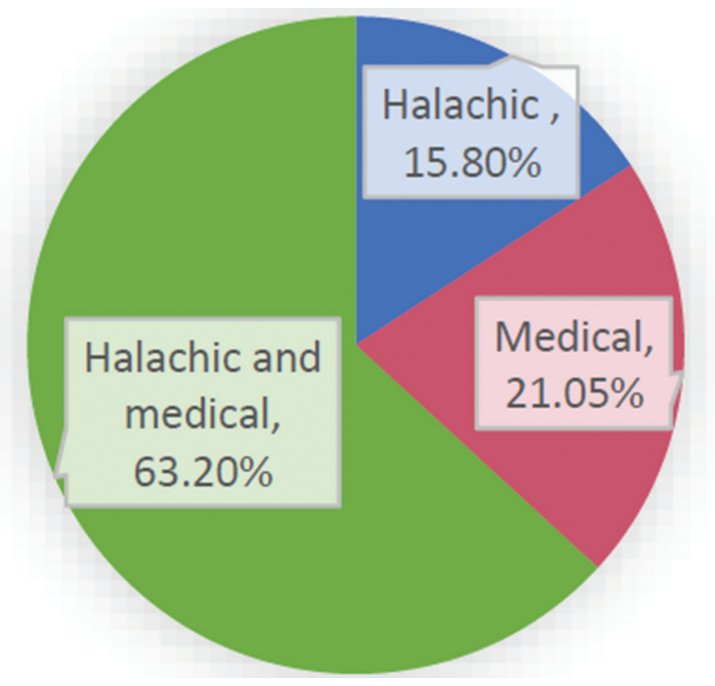

Figure 5. Most important motivation to seek treatment for pain during vaginal intercourse $(\mathrm{N}=19)$

Halachic: related to Halacha, the Jewish religious law; N: Number

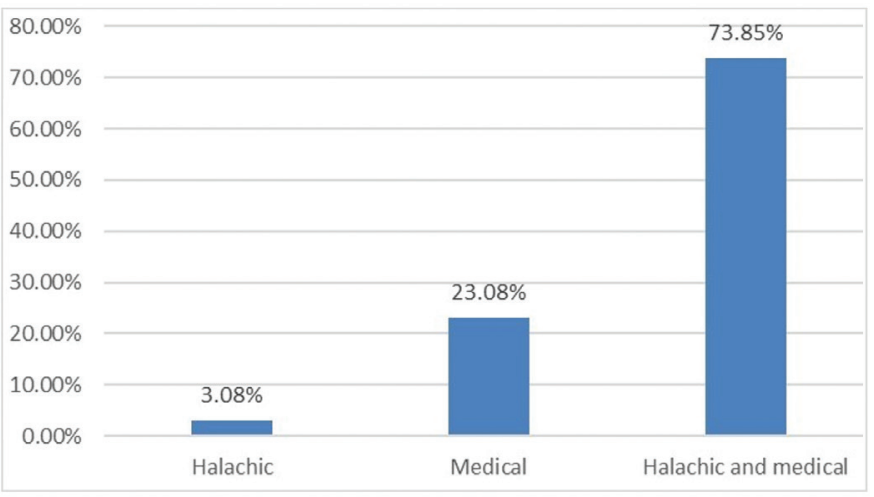

Figure 6. Main motivations for seeking physical therapy $(\mathrm{N}=65)$ Halachic: related to Halacha, the Jewish religious law; N: Number 
pelvic floor impairment was reported to be the most worrisome (mean=4.98, SD=0.14), followed by the feeling that their physical condition causes them to be ashamed in front of their husbands (mean $=4.75, S D=0.74$ ). The least worrisome situation was urinary incontinence (mean $=4.00, S D=1.18$ ), though it should be noted that the score, however, indicates a high degree of motivation to seek immediate treatment.

\section{DISCUSSION}

The most common motivations for women seeking treatment for pelvic floor disorders involved both medical and Jewish religious law motivations, which supports the research hypothesis. Of the 65 women who completed the questionnaires, only two indicated solely Jewish religious law motivations, whereas 15 noted solely medical motivations.

Between $7 \%$ and $37 \%$ of women in this study aged 20 to 39 years reported a certain level of incontinence, and nearly half of all women reported symptoms of POP. Many women are diagnosed by their gynaecologist as suffering from slight prolapse; however, it will not always be felt or accompanied by symptoms. ${ }^{11}$ POP can cause symptoms such as loss of urine, difficulty in emptying the intestines, pain in the lower back or pelvis, pain or discomfort while having sexual intercourse, and decreasing self-image and quality of life..$^{10,12}$

Ultra-orthodox women have an obligation to pray, which cannot be done if she is viewed as unclean. ${ }^{13}$ Urinary or fecal incontinence will prevent a woman from praying, and bleeding due to POP prevents immersion in the ritual bath-the Mikveh. ${ }^{14}$ In the worst-case scenario, if an ultra-orthodox woman prays while she is seen as unclean, her prayer would be considered an abomination as if she had not prayed at all. ${ }^{15-17}$ For an ultraorthodox woman, this seriously impairs a religious way of life.

Pelvic floor disorders are also unpleasant and awkward from a personal and conjugal perspective. While this is common to all women, there are additional Jewish religious law implications for ultra-orthodox women. ${ }^{18}$ Pain or difficulty in sexual relations can occur as a result of over-contraction of the pelvic-floor sphincters or due do provoked vulvodynia-oversensitivity of the vestibule. ${ }^{19}$ Additionally, it can arise among couples during sexual intercourse when the woman experiences different forms of pain in the pelvic area. The pain impairs daily functioning and prevents the possibility of sexual contact. ${ }^{20}$ This situation causes many couples to avoid intercourse, and as a result, it prevents an essential part of Jewish religious marital life, as well as procreation. ${ }^{21,22}$

We discovered that among women experiencing urinary incontinence, the effect on their ability to fulfil religious commandments was significant and difficult. However, there was no significant difference in the proportion citing combined medical and Jewish religious law motivations for seeking treatment and those citing only Jewish religious law motivations. A higher proportion of women reported combined motivations for seeking treatment for prolapse; however, several women reported that they would immediately seek treatment if the prolapse led to difficulties or delays with immersion in the ritual bath. Among those who sought treatment due to difficulties during intercourse, combined Jewish religious law-medical motivations were the most common, and women indicated a strong correlation between the ability to fulfil commandments and bodily functioning. This symptom, in particular, influences both the woman's personal life and her relationship with her partner. Thus, when there is Jewish religious law difficulty in addition to a medical dysfunction, the consequences are more severe and affect quality of life, and it motivates religious women to actively seek out treatment.

Bilu and Witztum ${ }^{23}$ suggest that the starting point in the dialogue of the healthcare provider with ultra-orthodox women must consider understanding that religion is what provides the main set of emotions through which their illness is experienced. On this basis, therapeutic approaches can be creatively integrated into spiritual-religious elements. ${ }^{23}$

The study is novel in examining the religious motivations behind seeking therapy for symptoms associated with POP. However, no control group was included in this study.

Multidisciplinary teams of medical professionals who treat women with pelvic floor disorders should be prepared to treat patients from diverse cultural/ethnic and religious backgrounds. ${ }^{24}$

\section{CONCLUSIONS}

Caregivers engaging in these sensitive and intimate issues should recognize not only the language and terminology unique to diverse populations but also the factors that motivate them to seek treatment for these issues. This study demonstrated that the importance of Jewish religious law in the eyes of ultraorthodox women is integrated into their daily lives and shapes their care-seeking behavior.

\section{Ethics}

Ethics Committee Approval: This study was performed in line with the principles of the Declaration of Helsinki. The IRB at Galilee Medical Center (Helsinki Committee) approved this study (approval number: 0058-20-NHR, given on July 21 ${ }^{\text {st }}, 2020$ ).

Informed Consent: Patients who met the inclusion criteria received an explanation of the methods and procedures of the 
study, and if they were interested in participating, they signed an informed consent form.

Peer-review: Externally peer-reviewed.

\section{DISCLOSURES}

Conflict of Interest: The authors have no conflicts of interest.

Financial Disclosure: The authors declared that this study has received no financial support.

\section{REFERENCES}

1. Bump RC, Norton PA. Epidemiology and natural history of pelvic floor dysfunction. Obstet Gynecol Clin North Am 1998; 25: 723-46.

2. Minassian VA, Drutz HP, Al-Badr A. Urinary incontinence as a worldwide problem. Int J Gynaecol Obstet 2003; 82: 327-38.

3. Brown SJ, Gartland D, Donath S, MacArthur C. Fecal incontinence during the first 12 months postpartum: complex causal pathways and implications for clinical practice. Obstet Gynecol 2012;119:2409.

4. von Gontard A, Baeyens D, Van Hoecke E, Warzak WJ, Bachmann C. Psychological and psychiatric issues in urinary and fecal incontinence. J Urol 2011; 185: 1432-6.

5. Buckley BS, Lapitan MC; Epidemiology Committee of the Fourth International Consultation on Incontinence, Paris, 2008. Prevalence of urinary incontinence in men, women, and children--current evidence: findings of the Fourth International Consultation on Incontinence. Urology 2010; 76: 265-70.

6. Eason E, Labrecque M, Marcoux S, Mondor M. Anal incontinence after childbirth. CMAJ 2002; 166: 326-30.

7. Haylen BT, de Ridder D, Freeman RM, et al. An International Urogynecological Association (IUGA)/International Continence Society (ICS) joint report on the terminology for female pelvic floor dysfunction. Int Urogynecol J 2010; 29: 4-20.

8. Bo K, Frawley HC, Haylen BT, et al. An International Urogynecological Association (IUGA)/International Continence Society (ICS) joint report on the terminology for the conservative and nonpharmacological management of female pelvic floor dysfunction. Neurourol Urodyn 2017; 36: 221-44.
9. Gyhagen M, Bullarbo M, Nielsen TF, Milsom I. Prevalence and risk factors for pelvic organ prolapse 20 years after childbirth: a national cohort study in singleton primiparae after vaginal or caesarean delivery. BJOG 2013; 120: 152-60.

10. Roets $L$. The experience of women with genital prolapse. Curationis 2007; 30: 7-14.

11. Weisberg E, Kern I. Judaism and women's health. J Fam Plann Reprod Health Care 2009; 35: 53-5.

12. Åkervall S, Al-Mukhtar Othman J, Molin M, Gyhagen M. Symptomatic pelvic organ prolapse in middle-aged women: a national matched cohort study on the influence of childbirth. Am J Obstet Gynecol 2020; 222: 356.

13. Talmud Bavli. Tranctate Berachot [Heb.]. Jerusalem: Tal-Man, 1981.

14. Shemesh A. 'Holi Hashvira' [Heb] (Hernia and Uterine Prolapse) according to the Responsa Literature, Assia 2004; 73-74, 104-17.

15. HaKohen YM. Mishnah Berura [Heb.]. Jerusalem: Da’at Yosef, 1993.

16. Maimonides M. Mishneh Torah [Heb]. Jerusalem: Machon Mishnat HaRambam, 1985.

17. Melamed E. Peninei Halakha: Nashim [Heb.]. Israel: Machon Har Bracha, 2006.

18. Schreiber M. Teshuvot Hatam Sofer [Heb], 1903.

19. Bornstein J, Goldstein AT, Stockdale CK, et al. 2015 ISSVD, ISSWSH, and IPPS consensus terminology and classification of persistent vulvar pain and vulvodynia. J Sex Med 2016; 13: 607-12.

20. Rosenbaum TY, Barnard E, Wilhite M. Psychosexual Aspects of Vulvar Disease. Clin Obstet Gynecol 2015; 58: 551-5.

21. Ribner DS, Rosenbaum TY. Evaluation and treatment of unconsummated marriages among Orthodox Jewish couples. J Sex Marital Ther 2005; 31: 341-53.

22. Caro Y. Shulhan Arukh [Heb.]. Jerusalem: B.B publication Ltd. Mea Shearim st, 1976; 91.

23. Bilu Y, Witztum E. Culturally sensitive therapy with ultra-orthodox patients: the strategic employment of religious idioms of distress. Isr J Psychiatry Relat Sci 1994; 31: 170-82.

24. Baumel S. Sacred Speakers: Language and Culture among the ultraOrthodox in Israel. Berghahn Books, 2006; 24. 